\title{
Competencies and Skills: Filling Old Skins with New Wine
}

\author{
Christina Dörge \\ University of Oldenburg, Computer Science Education, \\ 26111 Oldenburg, Germany \\ Christina.Doergedinformatik.uni-oldenburg.de
}

\begin{abstract}
Key competencies", "key skills" and "key qualifications" are buzzwords so prominently featured in contemporary scientific treatises that discussions have been prompted about an inflationary use of the terms and what they really should be taken to mean. A similar situation exists in the field of ICT and CS education: What meaning should we ascribe to terms such as "skill", "competency" and "qualification" and what should be taught as "basic information technology"? These questions merit a closer look, especially since the idea of teaching competencies received a new updraft in Europe by the BolognaDeclaration, and the teaching of basic ICT and / or CS skills is still a difficult issue in the educational sciences. This paper wants to provide insight into the discussion on skills in Anglo-American and German scientific research and wants to act as a call for more clarity in definitions and concepts regarding IT skills.
\end{abstract}

Keywords: Key competencies, key skills, IT, ICT and CS education, BolognaDeclaration.

\section{Introduction}

Today, computer technology can be found nearly everywhere. Most of us are in some way affected by developments in the field of Information Technology (IT), Information and Communication Technology (ICT) and Computer Science (CS). In 1985, Klafki stated that a basic education in computer science-related fields is important to equip young people with the knowledge they need to play a valuable part in the future of society (see [18], p. 60). There are several reasons why ICT knowledge is important: Computers now touch nearly every aspect of our working lives, even in jobs not immediately associated with computer science. The Computer Science and Telecommunication Board (CSTB) stated that the broad category of knowledge-workers make use - in one sense or the other - of information technology. The library science community of the US has compiled a list of skills which are important for finding, evaluating and using data (see [7], p. vii). The information flood we face every day affects us not only in our professional lives. In addition, the increasing impact on the economy is another important reason to learn how to use information technology efficiently. Hence it can be argued that a basic education in information technology is important for everyone. 
One of the biggest obstacles arising for those who develop basic IT education courses or curricula is that IT / ICT / CS knowledge often has a rather short lifetime: Jaeger cites Charlier et al. and Staebler ${ }^{1}$, who both give a half-life period of approximately 6 to 12 months for IT / ICT / CS knowledge (see [17], p. 148f; [6], p. 120; [29], p.148ff).

This leads over to another issue, the Bologna-Declaration, which was signed in 1998 by the four secretaries of education of France, Italy, Great Britain and Germany. One of the declaration's primary goals is to bring change to teaching styles at universities, a transition from the traditional idea of "content based"-learning towards "teaching key competencies".

With this, the discussion about "life long learning" was rekindled. Teaching key competencies appears to provide an answer to an important problem: Pupils and students are not equipped with the skills currently required by the job market. Even if they were, their knowledge would not last due to the rapidly changing nature of computer technology. Thus the education process bypasses pupils and students by not teaching them persistent knowledge and skills. What they need are ideas and patterns to acquire skills for life long learning. The notions of "competencies" and "key skills" seem to offer a way out of this dilemma. However, the most often practiced approach in IT / ICT / CS courses is to teach "user knowledge" (as a superficial product training might do) instead of the underlying concepts. This is not a good way to enable people to use or access new technologies or interest them in IT- / ICT- or CS-related jobs.

The dissertations of Doerig, Orth, and Jaeger address the concept of competencies (in general) and their possible implementation strategies (see [11], [25], and [17]). The more specific question what "key competencies" might mean in the field of computer technology has not been answered yet.

In the following chapters a brief chronological overview of the concepts of "key qualifications" and "key competencies" will be given - from the perspective of German (section 2) as well as from Anglo-American research (section 3). In addition, some insights in the development of ICT / CS standards will be presented in section 2 .

\section{The German Discussion on Competencies and Qualifications}

Before it is possible to work on questions such as "How can I include the teaching of skills in my courses?" or "How can I teach competencies?", a few words are in order about what constitutes a competency and what makes a qualification. There are several problems: Some authors use the terms synonymously, others don't. With a closer look it also becomes obvious that not all authors talk about the same group of concepts. The reverse phenomenon, i.e. authors using different terms for what are essentially the same ideas and concepts, can also be found (see [17], p. 65ff).

However, there is evidence that a difference exists between "competency" and "qualification", as the researchers of the work group "Hochschul-InformationsSystem (HIS)” wrote in [28], p.1 $1^{2}$ : ,The terms „competency“, „, key competency“ and

\footnotetext{
${ }^{1}$ They speak about "EDV-Wissen" (EDV = electronical data processing, Wissen $=$ knowledge $)$, which describes more or less the usage of informatics systems and has its roots in the 50s, as established by IBM.

${ }^{2}$ Translated from German by C. Dörge.
} 
„key qualification“ pose a challenge. With changing theoretical background and usage the terms are defined differently. Their description is marked by vagueness and a deficiency in applicability. “

\subsection{Mertens's Concept of Key Qualifications}

Mertens, coming from the field of "Vocational Education", is often mentioned as the first who raised the term "key qualification" ${ }^{3}$ in 1974 . His aim was to initiate a discussion about the changing situation for people in the job market: He knew that some of the market's fundamentals had changed and that it was therefore necessary to adapt education to the new requirements. Mertens breaks "key qualification" (KQ) down into four subjects (see [21], p. 36) ${ }^{2}$ :

1. Basic qualifications (e.g. structured and logical thinking),

2. Horizontal qualifications (e.g. transfer of knowledge about one foreign language to another),

3. Ubiquitous elements (cross-educational requirements such as basic arithmetic), and

4. Vintage factors (e.g. expiration of applicability of knowledge acquired at educational institutions).

The term "key qualification" was very frequently used in scientific publications and discussions. More and more it was felt that an "uncontrolled growth" with regard to the variety of meanings of the term had taken place. Therefore, the "Bundesinstitut für Berufsbildung (BIBB)" commissioned a survey: In 1999, Didi et al. discovered more than $600 \mathrm{KQ}$ terms in use in the field of vocational education (see [8], Appendix part one pp. 1- 11 and appendix part two pp. 1-4, also cited in [17], p. 65 and [25], p. 2). They compiled a list with the terms most often used in the literature. These $\operatorname{are}^{2}$ :

1. Ability to communicate

2. Ability to cooperate

3. Flexibility

4. Creativity

5. Associative thinking

6. Autonomy

7. Capacity to solve problems

8. Transferability

9. Willingness to learn

10. Ability to assert oneself

\subsection{Key Qualifications for the Acquisition of Competencies}

In 1999, Helen Orth, coming from the field of "Didactics in Higher Education", wrote her dissertation about several concepts used in the KQ discussion. Orth conducted a review of the field of KQ and gave a definition of "key qualifications" based on the

\footnotetext{
${ }^{3}$ In Germany, the idea was not new at that point: In the $19^{\text {th }}$ century, the first steps in this direction had been taken by the discussion of "formale Bildung", "materiale Bildung", and competencies.
} 
term "competency" ([25], p. 107) : "Key qualifications are acquirable common skills, attitudes, strategies and elements of knowledge which are useful in solving problems and in acquiring new competencies within as many scopes of content as possible. The goal is to gain an action ability which satisfies individual and societyrelated requirements."

This definition raises the question in which way key qualifications are related to competencies. It is important to note that what was generally termed KQ in 1999 is often called KC today.

\subsection{The "Action-Enabling Competency" as a Conceptual Focus}

Two years later, in 2001, Jaeger employed a different approach, giving definitions of the terms "qualification" and "competency" with an emphasis on their distinction (see [17], p. 70).

Jaeger, a pedagogue, gives a number of ideas on how competencies could be applied in schools. He rejects the term "key qualification" in favor of the idea of "key competencies" (KC), giving a detailed list of what competencies and qualifications are. As a resume, he offers a grouping concept for KCs: Four "specialized" competencies (professional, social, methodical and personal) are combined into one super-competency, the “action-enabling competency" (see [17], p. 78 for a detailed mind-map) ${ }^{4}$.

1. Professional competency: Competency in a profession, such as knowledge, skill, quality of work, working technique, endurance...

2. Social competency: Ability to work in a team, ability to accept criticism, openness...

3. Methodical competency: Structured thinking, to act creatively, to act in innovative ways, analytical investigation...

4. Personal competency: Creativity, self-confidence, flexibility, autonomy...

A concept of competencies in which the action-enabling competency is seen as a super-competency can now be found in many papers (see as examples: [27]; [2], p. 58).

A more general change has occurred as well: More and more scientific researchers have started to talk about "key competencies" instead of "key qualifications".

\subsection{The OCED-Report as World Wide Standard}

With the OECD-report "The Definition and Selection of Key Competencies" of 2005, we received a "standard definition" telling us what key competencies are. The paper was translated into several languages (English, German, Spanish, French, Italian and Japanese) and was created in close cooperation with the UNESCO (see [24], p. 8). It characterizes "key competency" as follows: "Key competencies involve a mobilisation of cognitive and practical skills, creative abilities and other psychosocial resources such as attitudes, motivation and values."

In a more detailed approach, key competencies are described by the OECD-report using "competency categories" (see [24], p. 10ff):

\footnotetext{
${ }^{4}$ Translated from German by C. Dörge.
} 
1) Using Tools Interactively (1A - The ability to use language, symbols and text interactively; $1 B$ - The ability to use knowledge and information technology; $1 C-$ The ability to use technology interactively)

2) Interacting in Heterogeneous Groups ( $2 A$ - The ability to relate well to others; $2 B$ - The ability to cooperate; $2 C$ - The ability to manage and resolve conflicts)

3) Acting Autonomously ( $3 A$ - The ability to act within the big picture; $3 B-$ The ability to form and conduct life plans and personal projects; $3 C$ - The ability to assert rights, interests, limits and needs)

The OECD's concept is not entirely new: Group 1) can be seen as "methodical competency", group 2) as "social competency" and group 3) as "personal competency" (compare with subsection 2.3). What may justifiably be described as "new" is the embedded aspect of IT (see category 1B and 1C). This aspect may be a starting point for further discussion: Its description is similar to the definitions found for "media competency", where critical and reflective use of media is the main focus. Hence the question arises whether it can cover the demand for a general CS-related education, which is our focus.

The definition used in the OECD-report is based on the competency definition of F.E. Weinert (see [31], p. 27f), a psychologist, and with this the discussion takes a new turn: The main factor of this competency definition is "measurability". The leading question for this approach might be: What is the value of an educational concept if we cannot evaluate its consequences? Here we must keep in mind that any measurement needs knowledge of the boundaries of the thing to be measured. If competencies "overlap across sections", their boundaries are not clearly defined and serious unsolved problems may arise from this in the future.

\subsection{From Input- to Output-Oriented Educational Standards}

There is a worldwide agreement that the purpose of a general education should be to enable learners to use their knowledge throughout the whole of their lives - not just on the job. Today it is believed that to achieve this, special competencies are needed.

In Germany, the traditional way to develop educational standards has been to describe the content to be taught. This changed with the discussion about competencies from an input-oriented approach to an output-oriented approach - competencies as the outcome of a successful education. But so far, output-oriented educational standards only exist for a few traditional subjects (e.g. mathematics, biology). In 2008, minimum standards for computer science and informatics courses for schools were developed and published by the "Gesellschaft für Informatik (GI)". These standards give a list of competencies which pupils should possess in the field of informatics by the end of the 10th grade (approx. age 16) of the German school system.

The GI educational standard is composed of two main sections, each of which contains several subsections (see [13], p. 11ff of the original report in German, and [5], p. 289f for an English article about this standard):

\section{The "Content Standards":}

- Information and data (e.g. connection between information and data, different types of data representation)

- Algorithms (e.g. knowledge of algorithms to execute tasks and solve problems from various fields of application) 
- Languages and automata (e.g. use of formal languages for interaction with informatics systems)

- Informatics systems (e.g. understanding of the basic concept of how an informatics system is built)

- Informatics, man, and society (e.g. knowledge of interchanges between informatics systems and society)

The "Process Standards":

- Model and implement (e.g. implementation of informatics models for given situations; reflection on models and their implementation)

- Reason and evaluate (e.g. use of criteria for the evaluation of informatics contexts)

- Structure and interrelate (e.g. the structuring of a given content by appropriate dissection and ordering of the problem; recognizing and using relations within and without the scope of computer science / informatics)

- Communicate and cooperate (e.g. communicating professionally about computer scientific subjects, co-operating to solve problems in informatics)

- Represent and interpret (e.g. interpretation of different representations of contents)

The aspects of the Content Standards must be seen as parts of a whole: Competencies may be gained by working within complex and interlocked contexts. Tasks assigned to pupils must respect this as a guiding principle (see [13], p. 23).

The Process Standards contains ideas about how to deal with the content, i.e. the operational methods used in the fields of computer science and informatics, e.g. the implementation of a model or the illustration of some given content. Learners acquire process competencies through their interaction with the content (see [13], p. 45).

With this, the group of experts of the GI provides standards to work with. How these can be transferred into a "competency model" can be found in the dissertation of Kohl (see [19]). But what is missing in these standards is a definition of the term "competency".

\subsection{Summary of This Section}

Many scientists have used the first approach of Mertens. Unfortunately, this has resulted in a proliferation of KQ concepts rather than in unification and more clarity. Some scientists, like Orth and Jaeger, became aware of this and tried to streamline existing concepts and definitions. After some time, the "action-enabling-competency" was used as a focal point for concepts of competency. In 2005, the OECD-report set a landmark by defining their concept of key qualifications, which includes personal-, methodical- and social competencies, as well as an embedded aspect of IT. The educational standards described in subsection 2.5 were a first approach to describe those kinds of competencies which might cover the demands for a general CS-related education. What is missing in all those standards is a definition of what the term "competency" should be taken to mean. Several German scientific researchers in ICT and CS use the definition of competency by F.E. Weinert (for an example see [30], p. 13; [20], p. 1). This definition seems to be very handy since it offers "measurability". But we have to keep in mind that not all definitions of "competency" include that 
aspect: Some researchers maintain that competencies are not output oriented and therefore not measurable (see e.g. [17], p. 146).

\section{The English Discussion on Competencies and Skills}

In the English competency discussion, several critical terms are construed differently: It does not focus on a "competencies" versus "qualifications" distinction but on different forms of "skills" and "competencies". The term "qualification" as used in Anglo-American research usually refers to "a formal degree" while in Germany "qualification" also means "ability". The German term for "ability" ("Fähigkeit") on the other hand is often translated as "competency" (see also [26], Annotation).

However, the terms in the English discussion are prone to cause confusions as well.

\subsection{Different Types of Skills}

Taking a look at the English discussion shows that many scientific works use the terms "skill" and "competency". Especially the terms "generic skills" and "core skills" show up quite often.

Bennet, Dunne and Carré wrote (see [3], p. 74): “The conceptualisation of core skills is problematic for several reasons. The term has several synonyms, including personal transferable, key, generic, common, and work or employment related skills. To add to this semantic confusion, these skills are often referred to as competences, capabilities, attributes, elements or learning outcomes, sometimes incorporating levels and sometimes not. Similarly, the various lists of skills elicited from employers, and contained in government reports, are diverse in both extent and purpose, reflecting differences in definitions and interpretations of their significance."

This citation gives some insight into the situation of the English discussion and suggests that it is similar to the German one described in section 2. It is reasonable to assume that the quest for useful terms and concepts is a world wide problem.

Bennet, Dunne and Carré try to give a definition of different types of skills, e.g. "generic skills", by presenting a picture in their paper (see [3], p. 77), which contains four management skills "of self, others, information and task. These skills are generic in that they can potentially be applied to any discipline, to any course in higher education, to the workplace or indeed to any other context."

However, it may not always be possible to establish concepts of disciplinespanning competencies like this. E.g. a proper definition of "generic skill", "core skill" etc. may well depend on the discipline at which you choose to look (see [3], p. 80f).

\subsection{Questioning the Skills Agenda}

In 2000, Len Holmes wrote about "questioning the skills agenda" (the paper's title). His attempt is to bring more clarity to the discussion. For support of his views he refers to Hirsh and Bevan. These authors wrote about the situation of the job market and the "requirements of the skills and competencies of managers". They found that 
"there was a high level of agreement over the terms used," but "there was not agreement at the level of meaning" (see [16], p. 203 and [14]).

Similarly to the German situation with many different terms used as synonyms for "key qualification" (see Didi et al., section 2.1), there was a need to find and order all the terms in use for skills and competencies in the English speaking community. Holmes mentions Allen as a researcher who took a closer look at how many terms for skills other researchers had used (see [15], online document): Allen was part of a research project at Sheffield University which identified 108 "skills" (see [15]).

One of the main points of critique by Holmes is that "in many cases it seems that lists [of skills] have been drawn up by select groups of staff engaging in nothing more rigorous than a form of brainstorming". He continues: "Whilst such groups may gain a sense of achievement, the conceptual validity of their products must be surely be rated as low" (see [16], p. 205).

Holmes is not the only one who criticizes the conceptual work of his fellow researchers. In 2000, Bridges describes the situation of the skills discussion as a "conceptual mud" (see [5], p. 44).

As a positive example, Bridges refers to the "National Committee of Inquiry into Higher Education Report (NCIHE)" in the UK, which is often named as "The Dearing Report", and which "has given some authority both to the language of 'key skills' and the identity of these 'skills'” (see [4], p. 44). The DEARING REPORT gives four key skills, which are (see [23], paragraph 9.17):

- communication skills;

- numeracy;

- the use of information technology;

- learning how to learn

In paragraph 9.18 they add: "These are referred to as key skills throughout the remainder of our report. We believe that these key skills are relevant throughout life, not simply in employment. “

However "the use of information technology" does not imply knowledge in the field of CS. Therefore, further work may be necessary to ensure a successful basic education in CS.

\subsection{Skills in CS}

In 1997, in the US, the Computer Science and Telecommunication Board (CSTB) of the National Research Council initiated a study to address the subject of information technology literacy. The committee chose a broad definition of IT (see [7], p.viii): "Information technology was defined to include the more traditional components of information technology (such as general-purpose computational devices, associated peripherals, operating environments, applications software, and information), as well as embedded computing devices, communications, and the science underlying the technology." The aim of this study was to make people "fluent with information technology (FIT)", where the term "fluency" was used because it "connotes the ability to formulate knowledge, to express oneself creatively and appropriately, and to produce and generate information (rather than simply to comprehend it)" (see [7], p. viii and 
p.14). At the end, the term "FITness" was coined. While the above-mentioned definition does not mention competencies, it appears rather close conceptually. The CSTB gives a list of the ten highest-priority items for the three types of knowledge they have found, which are (see [7], p. 4): Intellectual Capabilities, Information Technology Concepts and Information Technology Skills. This report is meant for the highereducation community (colleges or universities), but it also offers comments on FITness for K-12 education (see [7], p. 51) ${ }^{5}$.

Another Informatics Curriculum Framework for Higher Education comes from the International Federation for Information Processing (IFIP), from 2000. It contains twelve core curriculum themes, including "concepts" and "skills" (see [22], p. 31ff):

1. Representation of Information

2. Formalism in Information Processing

3. Information Modeling

4. Algorithmics

5. System Design

6. Software Development

7. Potentials and Limitations of Computing and Related Technologies

8. Computer Systems and Architectures

9. Computer-Based Communication

10. Social and Ethical Implications

11. Personal and Interpersonal Skills

12. Broader Perspectives and Context (includes links with other disciplines)

This Curriculum offers a complete coverage of the informatics field and clarifies the relationship of informatics with other disciplines - which is a much broader approach then the one by the GI (see section 2.5).

\subsection{Summary for This Section}

The discussion about skills in the English speaking community has created several interesting ideas on curricula and standards as well as in the CS related field. What it has not produced is a definition of what skills are (besides simply listing examples). The terms "competency" and "key competency" are entirely absent.

\section{Conclusion}

In Germany, the discussion about competencies vs qualification ended with the (preliminary) result that competencies constitute the basis for the newly developed ICT / CS standards by the GI. The notion of competency used is one which includes measurability.

The Anglo-American discussion does not focus on competencies or qualifications, but on skills. They are the basis for UK and US standards, and the IFIP's as well. It

\footnotetext{
${ }^{5}$ In 2000, the International Society for Technology in Education (ISTE) of the US published three standards called NETS, which address the skills students / teachers / administrators should have, including CS related topics. (http://www.iste.org/AM/Template.cfm?Section=NETS, last checked on $30^{\text {th }}$ of January 2010).
} 
can be assumed that the notion of skill they use includes measurability. However, differently from the German GI-Standard, the US-version focuses on knowledge instead of skills and competencies, while the UK-version focuses on key skills. The IFIP-version centers on skills.

No definitions have been offered concerning what precisely the terms "skills", "key skills" or "competencies" should be taken to mean. Some researchers have given "definitions" by listing examples of competencies. It is a commonly accepted practice for scientists to use terms taken from colloquial language. However, an important part of scientific work is the clarification of those terms in order to avoid confusions and misunderstanding.

We have seen in this paper that there is a lot of groundwork still to be accomplished in order to achieve more clarity regarding the terms "skills", "competencies" and "qualification" - also in combination with the prefix "key". It would be instructive to see why a certain specific term was used in a research paper and not another one. This would make papers more comparable.

Finally, I would like to mention another aspect, one which goes beyond the scope of this paper. Should we transfer concepts of other areas of science into the competencies discussion of ICT and CS or should we try to develop our own concepts? There is no question that concepts from other scientific communities are applicable: Several papers, some of them mentioned in this one, have shown how to do it. It can also be shown that by teaching IT content, competencies can be gained - competencies such as those mentioned in the hit list in chapter 2 (see [10]). Competencies are not specific to ICT/CS or other scientific fields. Hence, a competency in "problem solving" (the ability to break down complex problems into smaller, more manageable parts) may refer to different concrete capabilities in different fields. Therefore, the aim should be not only to teach competencies, but "IT competencies". The competency of "problem solving" should be narrowed down to "problem solving in IT". This would constitute a new conception of competency which has not been covered by scientific research yet.

\section{References}

1. Allen, M.G.: A conceptual Model of transferable personal skills. Employment Department, Sheffield (1993), cited by [15] and [16]

2. Arnold, R., Arnold-Haecky, B.: Der Eid des Sisyphos - Einführung in die systemische Pädagogik. In: Arnold, R. (ed.) systhemia - Systemische Pädagogik, Band 1. Schneider Verlag Hohengehren GmbH, Baltmannsweiler (2009)

3. Bennett, N., Dunne, E., Carré, C.: Patterns of core and generic skill provision in higher education. Higher Education 37, 71-93 (1999), http: / /www. springerlink. com/ content/u6p58h83m8867827/ (05.10.09)

4. Bridges, D.: Back to the Future: the higher education curriculum in the 21 st century. Cambridge Journal of Education 30(1), 37-55 (2000)

5. Brinda, T., Puhlmann, H., Schulte, C.: Bridging ICT and CS - Educational Standards for Computer Science in Lower Secondary Education. In: ITiCSE 2009, Paris, France, pp. 288-292 (2009)

6. Charlier, M., Henke, R., Rother, F.: Medien für die Weiterbildung: Scheibe statt Flug. In: Wirtschaftswoche, vol. 48 (1994), cited in [17] 
7. Computer Science and Telecommunications Board (CSTB), National Research Council: Being Fluent with Information Technology. National Academy Press, Washington, DC (2000)

8. Didi, H.J., Fay, E., Kloft, C., Vogt, H.: Einschätzungen von Schlüsselqualifikationen aus psychologischer Perspektive, Bonn (1993)

9. Dörge, C., Schulte, C.: What are Information Technology's Key Qualifications? In: ITiCSE Conference Proceedings, Madrid, Spain, ACM Online Library (2008)

10. Dörge, C.: IT Key Qualifications For Students in Education. In: SITE Conference Proceedings, San Antonio, USA (2007)

11. Dörig, R.: Das Konzept der Schlüsselqualifikationen - Ansätze, Kritik und konstruktivistische Neuorientierung auf der Basis der Erkenntnosse der Wissenspsychologie. Dissertation, Hochschule St. Galen (1994)

12. Gesellschaft für Informatik (GI) e.V.: Grundsätze und Standards für die Informatik in der Schule - Bildungsstandards Informatik für die Sekundarstufe I. Beilage zu LOG IN, 28. Jg., Heft Nr. 150/151 (2008)

13. Hirsh, W., Bevan, S.: What Makes a Manager? In search of a language for management skills. In: Institute of Manpower Studies Report, No. 44, Institute of Manpower Studies, Brighton (1988), cited in [16]

14. Holmes, L.: The capability curriculum, conventions of assessment and the construction of graduate employability. Online-Document. Presented at Conference on 'Understanding the Social World', July 17-19. University of Huddersfield (1995), http://www.graduate-employability.org.uk/publications / CC_ca_gi.htm (verified: December 11, 2009)

15. Holmes, L.: Questioning the Skills Agenda. In: Fallows, S., Steven, C. (eds.) Integrating Key Skills in Higher Education - Employability, Transferable Skills and Learning for Life, pp. 201-214. Kogan Page Limited, London (2000)

16. Jäger, P.: Der Erwerb von Kompetenzen als Konkretisierung der Schlüsselqualifikationen: eine Herausforderung an Schule und Unterricht. Dissertation, Universität Passau (2001)

17. Klafki, W.: Neue Studien zur Bildungstheorie und Didaktik. Beltz Verlag, Weinheim (1985)

18. Kohl, L.: Kompetenzorientierter Informatikunterricht in der Sekundarstufe I unter Verwendung der visuellen Programmiersprache Puck. Dissertation, University of Jena (2009)

19. Kollee, C., Magenheim, J., Nelles, W., Rhode, T., Schaper, N., Schubert, S., Stechert, P.: Computer Science Education and Key Competencies. In: WCCE 2009, Brasilien (2009)

20. Mertens, D.: Schlüsselqualifikationen. In: Mitteilungen aus der Arbeitsmarkt- und Berufsforschung. Jg. 07, H.1, pp. 36-43 (1974)

21. Mulder, F., van Weert, T.: IFIP/UNESCO's Informatics Curriculum Framework 2000 for Higher Education. SIGCSE Bulletin 33(4) (2001)

22. NCIHE (National Committee of Inquiry into Higher Education): Higher Education in the Learning Society, The Stationery Office, London, Paragraphs 9.14-9.25 (1997)

23. OCED-Report: The Definition and Selection of Key Competencies - Executive Summary/ Definition und Auswahl von Schlüsselkompetenzen - Zusammenfassung/ La Définition et la Sélection des Compétences Clés - Résumé/ La definición y selección de competencias clave - Resumen (2005), http://www.deseco.admin.ch/bfs/deseco/en/ index/03.html (23.10.2009)

24. Orth, H.: Schlüsselqualifikationen an deutschen Hochschulen - Konzepte, Standpunkte und Perspektiven. Dissertation, Luchterhand Verlag, Neuwied (1999) 
25. Reetz, L.: Schlüsselqualifikationen - Kommentar. Auszug aus "Duales System zwischen Tradition und Innovation". In: Twardy, M. (ed.) Wirtschafts-, Berufs- und Sozialpädagogische Texte (WBST), Sonderband 4, pp. 27-46. Müller Botermann Verlag, Köln (1991), http: / / www-user.uni-bremen.de/ sept/current/deutsch/ $\mathrm{Pdf} / \mathrm{Ma}-\mathrm{A} / \mathrm{Ma}-\mathrm{A}-\mathrm{II} . \mathrm{pdf}$ (verified October 15, 2009)

26. Reetz, L.: Zum Zusammenhang von Schlüsselqualifikationen - Kompetenzen - Bildung (2003), http: / / www . sowi-online.de/reader/berufsorientierung/ reetz.htm (verified September 17, 2009)

27. Schaeper, H., Briedis, K.: Kompetenzen von Hochschulabsolventinnen und Hochschulabsolventen, berufliche Anforderungen und Folgerungen für die Hochschulreform. Hochschul-Informations-System (HIS) - Kurzinformation, A6 / 2004, Hannover (2004)

28. Stäbler, S.: Die Personalentwicklung der, Lernenden Organisation, Berlin (1999), cited in [17]

29. Stechert, P.: Fachdidaktische Diskussion von Informatiksystemen und der Kompetenzentwicklung im Informatikunterricht. Dissertation, Uni Siegen (2009)

30. Weinert, F.E.: Vergleichende Leistungsmessung in Schulen - eine umstrittene Selbstverständlichkeit. In: Weinert, F.E. (ed.) Leistungsmessungen in Schulen, pp. 17-31 (2002) 